Artigo Original

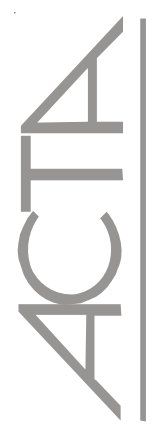

\title{
Avaliação da eficácia da pomada de própolis em portadores de feridas crônicas*
}

\author{
The effect of propolis cream in healing chronic ulcers \\ Evaluación de la eficacia de la pomada de própolis en portadores de heridas crónicas
}

\section{Marinaldo José dos Santos', Lucila do Amaral Carneiro Vianna ${ }^{2}$, Mônica Antar Gamba ${ }^{3}$}

\section{RESUMO}

Objetivo: Avaliar a evolução de úlceras crônicas utilizando a terapêutica tópica com a própolis. Métodos: Trata-se de um estudo descritivo onde foram identificadas vinte pessoas com feridas crônicas encaminhadas pelas Unidades Básicas de Saúde do Município de Maringá, Paraná. A análise baseou-se na avaliação e no tempo de cicatrização das feridas, realizada por meio do cálculo do Coeficiente de Correlação de Pearson para verificar a relação entre as medidas médias horizontais, verticais e de profundidades, a evolução do processo cicatricial. Resultados: $O$ acompanhamento de 22 úlceras crônicas permitiu observar por meio da análise estatística que a chance de cicatrização de todas as lesões foi de 13,1 semanas. Considerando um seguimento de 20 semanas 74,1\% das úlceras lograram cicatrização antes desse período. Quanto à etiologia, as úlceras venosas cicatrizaram em $35 \%$ (7) dos pacientes, contrapondo-se às úlceras de pressão cuja cicatrização ocorreu em apenas 10,0\% (2) dos pacientes. Conclusão: Concluiu-se, que a utilização da forma farmacêutica pomada de própolis, de fácil acesso e de baixo custo, foi eficiente na cicatrização de feridas.

Descritores: Cicatrização de feridas/efeitos de drogas; Própolis/uso terapêutico; Bandajens

\begin{abstract}
Objective: To evaluate the effect of propolis cream in healing chronic. Methods: This descriptive study used a sample of 20 subjects from a Basic Unit of Health of Maringá City, Paraná, Brazil, who had chronic wounds. Wound healing was measured through progress notes of wound length, width, and depth. Data were analyzed with Pearson's correlation to determine the degree and strength of the relationship between propolis cream treatment and wound healing. Results: The progress notes of 22 chronic ulcers showed that the probability of wound healing was 18.7 weeks. Regarding the study period of 13,1 weeks, the majority of ulcers $(74.1 \%)$ of ulcers healed completely. Regarding wound etiology, vascular ulcers (35\%) healed in 7 patients. And, pressure ulcers $(10 \%)$ healed in patients. Conclusion: The use of propolis cream, which is widely accessible and inexpensive, was effective in healing chronic wounds.

Descriptors: Wound healing/drug effects; Propolis/therapeutic use; Bandages
\end{abstract}

\section{RESUMEN}

Objetivo: Evaluar la evolución de úlceras cronicas utilizando terapéutica tópica con pomada de própolis. Métodos: Se trata de un estudio descriptivo en el cual fueron identificadas veinte personas con heridas crónicas encaminhadas por las Unidades Básicas de Salud del Municipio de Maringá, Paraná- Brasil. El análisis se basó en la evaluación y en el tiempo de cicatrización de las heridas, realizada por medio del cálculo del Coeficiente de Correlación de Pearson para verificar la relación entre las medias horizontales, verticales y de profundidad, o sea, la evolución del proceso de cicatrización. Resultados: El acompañamiento de 22 úlceras crónicas permitió observar, a través del análisis estadístico, que la probabilidad de cicatrización de todas las lesiones fue de 13,1 semanas. Considerando un seguimiento de 20 semanas el $74,1 \%$ de las úlceras lograron la cicatrización antes de ese período. En cuanto a la etiología, las úlceras venosas cicatrizaron en 35\% (7) de los pacientes, contraponiéndose a las úlceras de presión cuya cicatrización sucedió en apenas el 10,0\% (2) de los pacientes. Conclusión: Se concluye, que la utilización de pomada de própolis, de fácil acceso y bajo costo, fue sido eficiente en la cicatrización de heridas. Descriptores: Cicatrización de heridas/ efectos de drogas; Própolis/ uso terapéutico; Vendajes

\footnotetext{
* Artigo extraído da dissertação de Mestrado do Programa de Pós-Graduação de Enfermagem da Universidade Federal de São Paulo - UNIFESP - São Paulo, (SP), Brasil.

${ }^{1}$ Mestre em Ciências. Docente do Curso de Enfermagem do Centro Universitário de Maringá (PR), Brasil.

2 Professora Titular do Departamento de Enfermagem da Universidade Federal de São Paulo - UNIFESP - São Paulo (SP), Brasil.

3 Professora Adjunto da Disciplina de Administração aplicada e Enfermagem de Saúde Pública do Departamento de Enfermagem da Universidade Federal de São Paulo - UNIFESP - São Paulo (SP), Brasil.
} 


\section{INTRODUÇÃO}

Muitos fatores levam os profissionais de saúde, em especial o enfermeiro, a aproximarem-se da realidade dos pacientes, procurando, numa relação de troca, alternativas para atender as necessidades desta população. Profissionais e pacientes enfrentam mudanças na sociedade, refletindo nos aspectos psicológicos, espirituais e muitas vezes físicos. Frente a essas mudanças, há uma constante busca pelo bem-estar pessoal e social, ou seja, procura-se a qualidade de vida em todos os níveis. Assim, somando a busca pela qualidade de vida de pessoas com feridas crônicas, buscou-se uma forma farmacêutica que favorecesse a cicatrização.

Estudos demonstram as propriedades da solução hidroalcoólica de própolis como alternativa para o tratamento de protozooses em animais (coelho) e a utilização em soluções de continuidade (feridas), possibilitando a cicatrização, o que nos levou a propor o presente estudo ${ }^{(1-2)}$.

Focalizou-se a intervenção junto a pessoas portadoras de feridas crônicas para comprovação da eficácia da própolis na cicatrização de lesões. Essa ação culminou na colaboração para o melhor atendimento a ser prestado, envolvendo as equipes de enfermagem das Unidades Básicas de Saúde e das Unidades Hospitalares, esperandose maior qualidade e qualificação dos profissionais em toda sua integralidade.

Ao caminhar em direção às pessoas com feridas e seus familiares, tem-se como objetivo avaliar a eficácia da pomada de própolis em busca de subsídios científicos para a indicação da mesma como protagonista na cicatrização de feridas crônicas.

\section{MÉTODOS}

Este é um estudo descritivo baseado no estudo de $\operatorname{casos}^{(3)}$. Utilizou-se a descrição dos casos para determinar a freqüência da cicatrização das feridas em pessoas atendidas nas Unidades Básicas de Saúde; os curativos foram realizados diariamente, o registro da avaliação e das medidas semanalmente, identificando e descrevendo a evolução e as mudanças fisiológicas durante o processo de cicatrização das feridas, ou seja, as características relacionadas ao tipo de tecido no leito e na margem da ferida, tipo de exsudato e avaliação da dor e medidas. A assepsia da ferida, da pele e tecidos subjacentes foi feita por meio de irrigação em jato com soro fisiológico a $0,9 \%$, por meio do frasco de $125 \mathrm{ml}$ perfurado com agulha 40X12, após esse processo as feridas foram cobertas com cobertura não aderente. Os curativos nos domicílios seguiram as mesma técnicas e a duração da cicatrização dependeu do tempo de remodelamento da lesão(4-6) .
Para determinar a eficácia do estudo, avaliaram-se as variáveis sóciodemográficas e os efeitos desejados da pomada de própolis, a partir da evidência fisiológica e patológica da evolução das feridas, ou seja, os benefícios do tratamento em detrimento dos riscos. A efetividade foi avaliada registrando-se a condição da ferida com a documentação fotográfica, o tipo de tecido, presença de tecido necrótico, sinais de infecção, tipo de exsudato, volume e odor, exame microbiológico pela avaliação do swab, ou cultura de secreção, a mensuração das extensões verticais e horizontais com o paquímetro marca Sanny e a duração da ferida. Tais avaliações foram realizadas durante a execução dos curativos diários e por meio das consultas de enfermagem semanais.

Este estudo seguiu os protocolos necessários para atender o paciente e seus familiares, respeitando-os quanto à autonomia e defendendo-os em sua vulnerabilidade. No decorrer dos procedimentos foi respeitada a Resolução n. ${ }^{\circ}$ 196/96 do Conselho Nacional de Saúde, sobre pesquisa envolvendo seres humanos, tendo sido a proposta aprovada pelo Comitê de Ética em Pesquisa da Universidade Federal de São Paulo e assinado o Termo de Consentimento Livre e Esclarecido pelos pacientes e familiares.

Procurou-se por meio da definição do fenômeno estudado, avaliar a cicatrização de feridas pelo tempo de cicatrização com a indicação da pomada de própolis.

\section{POPULAÇÃO DE ESTUDO}

No período da coleta de dados foram selecionadas 20 pessoas, com 22 feridas crônicas de diferentes etiologias, tais como: úlceras vasculares, diabéticas e por pressão, de ambos os sexos e faixas etárias. A seleção foi realizada de forma aleatória sob indicação das Equipes de Saúde da Família das Unidades Básicas de Saúde. Foram realizados 2011 curativos e 156 evoluções durante a realização do estudo.

\section{ANÁLISE ESTATÍSTICA}

Para avaliação do processo cicatricial, utilizou-se a técnica de medição por meio das medidas de comprimento, largura e profundidade das feridas, verificando-se, por meio do Coeficiente de Correlação de Pearson, a relação entre as medidas médias horizontais $(\mathrm{MH})$, verticais (MV) e de profundidades (MP), e o tempo de cicatrização foi estimado pela análise de sobrevivência. A opção pelo Coeficiente de Pearson permitiu estudar o grau de associação "linear", ou seja, a correlação entre as medidas. Os resultados apresentados neste estudo referem-se ao tempo de cicatrização ${ }^{(7)}$. 


\section{RESULTADOS}

Foram identificadas 20 pessoas com 22 feridas crônicas: onze úlceras venosas $(50,0 \%)$; sete úlceras por pressão $(30,0 \%)$, duas úlceras diabéticas $(10,0 \%)$ e duas com ferida pós-trauma $(10,0 \%)$.

Em relação as variáveis sóciodemográficas observouse certa homogeneidade entre os indivíduos. A idade média das pessoas foi de 69,1 anos, predominando a cor branca $(95,0 \%)$ e o sexo feminino $(55,0 \%)$. Os indivíduos casados representaram $45,0 \%$ da população investigada, contrapondo-se a 30,0\% de solteiros e $25,0 \%$ de viúvos. Houve predomínio da ocupação 'Do lar', em 50,0\% das pessoas, seguido de 35,0\% de aposentados e 15,0\% em atividade profissional. Os indivíduos ativos profissionalmente eram os mais jovens, com média de idade de 33 anos.

Verificou-se a ausência de dependência química, tabagismo e etilismo, em $25,0 \%$ e 75,0\%, respectivamente. Quanto aos hábitos de vida, à dependência do tabaco no passado, observou-se que 45,0\% nunca fumaram e 30,0\% referiram já haver fumado. Analisando estes dados, comprova-se que 55,0\% dos entrevistados fazem ou já fizeram uso do tabaco. Em relação as variáveis clínicas, houve o predomínio da presença da Hipertensão Arterial, em 55,0\% dos casos; seguido de Acidente Vascular Cerebral e 10,0\% de pessoas com Diabetes Mellitus; as demais, foram: hipercolesterolemia, depressão e síndrome de Down (5,0\% cada). Quanto ao tempo de evolução das feridas, verficou-se que a maior parte das mesmas (53,0\%) existia há menos de um ano. Quanto à localização, as de etiologia venosa estavam localizadas na região da tíbia $(30,0 \%)$ e região maleolar do membro inferior direito e esquerdo (20,0\%); nas úlceras de pressão, região sacrococcígea $(15,0 \%)$; calcâneo $(10,0 \%)$; ísquio (5,0\%); trocanter esquerdo $(5,0 \%)$ e escápula $(5,0 \%)$; na úlcera diabética na região maleolar $(5,0 \%)$ e na região patelar a ferida traumática (5,0\%). Durante a avaliação do tipo de tecido registrou-se a presença de tecido necrótico em 14 avaliações $(8,2 \%)$ e a total ausência do mesmo, após a intervenção com a terapêutica neste grupo e em 156 evoluções, ou seja, 91,8\% durante o seguimento. A presença de exsudato seroso, com odor sui generis estava presente em 134 (78,8\%) das evoluções. $\mathrm{Na}$ avaliação da intensidade volumétrica desses exsudatos, detectou-se pouca intensidade em $92(54,1 \%)$ das ocorrências, seguido de moderada, com 48 (28,2\%), acentuada, em 19 (11,2\%) e a sua ausência em 11 curativos (6,5\%). Estas secreções caracterizaram-se pela predominância de serosas em 150 ocorrências (88,2\%); seguidos de sero-sanguinolentas, em 12 (7,1\%); purulentas, em 7 (4,1\%); e sanguinolentas, em apenas um caso $(0,6 \%)$. Quanto ao odor avaliado nas evoluções realizadas, percebeu-se, durante o seguimento com a terapêutica própolis, a ausência do mesmo em 91
(53,5\%) dos casos. Questionando os portadores de feridas crônicas, submetidos ao tratamento em questão sobre a intensidade da dor, com escala analógica, a maioria (42,9\%) referiu a presença de dores leves, 14,1\% moderada, contra $4,7 \%$ que apresentaram dor intensa; enquanto $38,2 \%$ não referiram nenhuma sensação dolorosa. O efeito analgésico pôde ser observado durante o seguimento com a pomada de própolis, os pacientes referiram melhora da dor e do calor local; diminuição do odor, do 'inchaço', da secreção e da 'coceira'. Ao exame físico, esses aspectos foram observados e detectou-se melhora do aspecto das lesões, diminuição do edema e da quantidade de secreções. Gradativamente, o tecido de granulação surgiu no leito da maioria das feridas. Camadas de tecido esfacelado foram observadas e a lipodermatoesclerose esteve presente nas pessoas com diagnóstico de úlceras venosas. Pele descamativa, presença de queratina, rachaduras e hipoidrose foram também registradas durante as avaliações.

Nas úlceras por pressão observou-se, com freqüência, exsudatos de coloração acastanhada, odor fétido, com grande quantidade de esfacelo, presença de crosta liquefeita, hiperqueratose aderida nas bordas, pontos de hiperpigmentação, presença de sinus cavitário, que evoluíram para a fase de maturação e de remodelação, após a intervenção terapêutica com a propólis.

\section{Avaliando o processo cicatricial}

Para avaliação deste processo utilizou-se a técnica de medição por meio das medidas de comprimento, largura e profundidade das feridas.

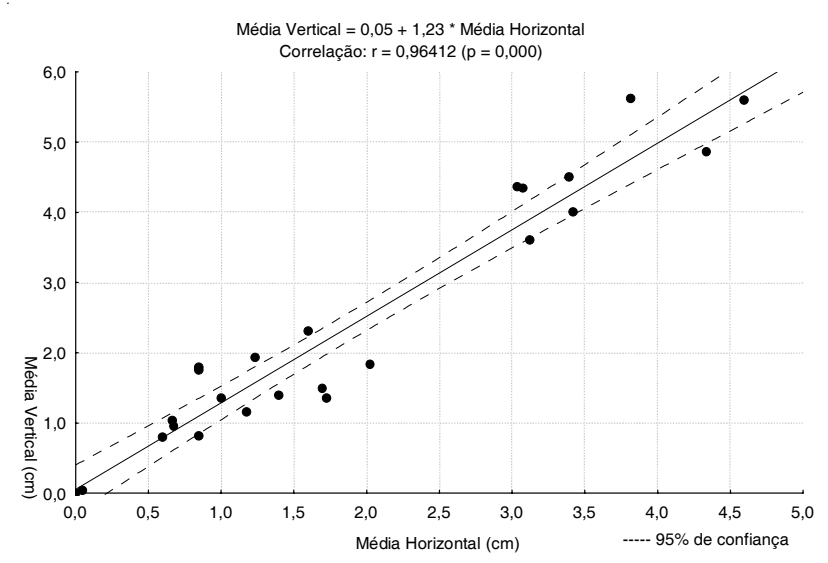

Figura 1 - Gráfico da Correlação entre Medida Média Horizontal e Vertical.

Verificou-se por meio do Coeficiente de Correlação de Pearson se havia correlação entre as medidas médias horizontais $(\mathrm{MH})$, verticais (MV) e de profundidades (MP) na evolução do processo cicatricial, ou seja, o grau de associação "linear" entre elas. Ao observar a equação de 
relação entre MV e MH, visualiza-se que para cada unidade $(\mathrm{cm})$ de diminuição da média horizontal, tem-se uma diminuição média vertical na ordem de 1,23 cm.

\begin{tabular}{|l|c|c|c|}
\hline Medida & Média & Mediana & Desvio Padrão \\
\hline Vertical & 2,374825 & 1,775000 & 1,743931 \\
\hline Profundidade & 0,169441 & 0,120000 & 0,175031 \\
\hline Horizontal & 1,882493 & 1,500000 & 1,364031 \\
\hline
\end{tabular}

Análise de "Sobrevivência" ou Tempo de Cicatrização de Feridas, utilizando o tratamento com própolis

Para esta análise apresentamos as seguintes

Codificações das Variáveis Analisadas:

* Nome: Identificação do paciente

* Tempo: Tempo de Cicatrização em semanas

* Censura:

1 - se ocorre cicatrização

0 - se não ocorre cicatrização ou desistência ou óbito

* Sexo:

1 - Masculino

2 - Feminino

* Idade: Idade em anos

* Tempo de Existência: Tempo de existência da ferida em semanas, antes do tratamento

Observou-se que o tempo médio estimado para a cicatrização foi de 15,12 (d.p. $=2,42)$ semanas, sendo a mediana a mais adequada já que a distribuição dos tempos é assimétrica. Logo, uma estimativa não paramétrica para o Tempo de Cicatrização é de 13,10 e seu respectivo intervalo com 95\% de confiança é de (12,90; inf.) (Tabela 1).

Neste contexto, o termo "Sobrevivência" da ferida significa "Probabilidade de não cicatrizar". Desta forma, pode-se observar, por exemplo, que com 18,7 semanas (aproximadamente 5 meses) a probabilidade (chance) de cicatrização é de aproximadamente 82,09 \% (1 - 0,1791), ou de não cicatrizar de 17,91\%.

Observando-se as diferenças nos tempos de cicatrização das feridas em relação ao sexo dos sujeitos da pesquisa, procedeu-se uma análise para verificar se esta diferença era significativa. Observou-se diferença na probabilidade de sobrevivência (não-cicatrização) para os indivíduos do sexo masculino em relação ao sexo feminino, isto é, a probabilidade de não cicatrização é maior entre o sexo masculino (Tabela 2).

\section{DISCUSSÃO}

Os problemas socioeconômicos que afetam as pessoas com úlceras crônicas de membros inferiores são apontados por diversos estudos como geradores de aposentadorias precoces e afastamentos prolongados do trabalho. A incidência das úlceras venosas é de 1,1 a 3,0 por 1000 , o que corresponde a $60 \%-80 \%$ entre as pessoas afetadas por feridas crônicas ${ }^{(8)}$.

Os indivíduos com idade mais avançada apresentaram reações mais lentas frente ao processo de cicatrização, devido ao retardo da granulação e da resposta inflamatória. Idosos apresentam baixa resistência à tensão e baixa taxa de epitelização, tendo como efeito geral do envelhecimento a dificuldade de cicatrização e alto risco de ruptura múltipla de feridas ${ }^{(4)}$.

O tabagismo, como a dislipidemia, obesidade, sexo masculino, vida sedentária e fator familiar são apontados como predisponentes da aterosclerose ${ }^{(7)}$. Vários estudos indicam o uso de apenas água, sabão e repouso para a cicatrização, identificando que os mesmos eliminam o fator causal da úlcera venosa - a hipertensão venosa. Além destes cuidados, a intensificação do tratamento compressivo é uma das medidas mais importantes, bem como a manutenção do curativo úmido e não-aderente nos diferentes tipos de úlceras ${ }^{(7)}$. Somado a estes fatores, a própolis com suas atividades antibacteriana, antifúngica e seu efeito cicatrizante contribui efetivamente para a cicatrização $^{(9)}$.

A referência ao uso de medicamentos pelos entrevistados esteve presente em $75,0 \%$, seguido da não utilização de medicamentos em $25,0 \%$; como a média de idade da população em estudo foi de 69,1 anos, evidencia-se o aumento de uso de medicamentos, principalmente o uso contínuo de antidepressivos, sedativos, ansiolíticos, diuréticos e hipotensores, podendo interferir no processo de cicatrização. Os antiinflamatórios não-esteroidais (AINE) interferem diretamente na síntese de colágeno e automaticamente diminuem a resistência à tensão da ferida, interferindo diretamente na migração dos leucócitos para a ferida, causando susceptibilidade á infecção. Alguns antibióticos também prejudicam a cicatrização devido ao seu efeito citotóxico ${ }^{\mathrm{e}}$ esse não foi observado com a utilização da pomada de própolis ${ }^{(2,4)}$. A utilização da pomada própolis produziu efeito analgésico e a redução do consumo de terapêuticas sistêmicas evidenciado por outras publicações ${ }^{(2,9)}$.

O tecido desvitalizado e o edema favorecem a multiplicação bacteriana, o aparecimento da infecção e o

Tabela 1 - Estimativa para o tempo de cicatrização (semanas) via Kaplan-Meier (não paramétrica)

\begin{tabular}{|c|c|c|c|c|c|c|}
\hline $\mathrm{N}$ & Observações (\%) & Censuras (\%) & média & Desvio-padrão & mediana & IC $(95 \%)$ \\
\hline 22 & 59 & 41 & 15,12 & 2,42 & 13,10 & 12,90 \\
\hline
\end{tabular}


Tabela 2 - Teste de Log-Rank para os tempos de cicatrização em relação ao sexo

\begin{tabular}{|c|c|c|c|c|c|}
\hline Sexo & $\mathrm{N}$ & O (Observados) & E (Esperados) & $(O-E)^{2}$ & $(O-E)^{2}$ \\
\hline & & & & $E$ & $V$ \\
\hline Masculino & 10 & 5 & 5,65 & 0,0750 & 0,148 \\
\hline Feminino & 12 & 8 & 7,35 & 0,0577 & 0,148 \\
\hline
\end{tabular}

retardo da cicatrização. A baixa concentração de oxigênio $\left(\mathrm{O}_{2}\right)$ facilita a necrose e multiplicação microbiana, principalmente nas feridas infectadas por Staphylococcus aureus, Proteus vulgaris, Klebsiela pneumoniae, E. coli, Salmonellas thyphimurium, onde a hipóxia impede a destruição dos microorganismos pelos leucócitos ${ }^{(2,8)}$. Ao registrar a presença de sinais de infecção, foi possível observar as ações específicas da própolis, avaliando sua eficácia como ações antibacteriana, antifúngica, entre outras. Foi possível observar, clinicamente, que a ausência de sinais de infecção ocorreu em 105 (61,8\%) evoluções e a presença em $65(38,2 \%)$ evoluções.

Os respondentes indicaram, freqüentemente, que a presença de um ferimento por um longo período de tempo e a busca incessante por tratamentos tradicionais os desestimularam à crença na cura da lesão. Durante as avaliações semanais, observou-se a evolução gradativa dos sinais e sintomas característicos das feridas e as ações da pomada de própolis da fase inflamatória à fase de epitelização. Existem situações que impedem a evolução normal do processo de cicatrização, como a presença de necrose, suprimento sanguíneo reduzido, infecção local, radiação, tipo de cobertura, comprometimento nervoso, entre outros; além dos fatores sistêmicos, representados pela idade, patologias, infecção e uso de drogas ${ }^{(9)}$. Durante a realização dos curativos esses valores mudaram ao observarem-se alterações significativas na diminuição do ferimento. Em virtude dos avanços tecnológicos e dos estudos realizados com a própolis percebe-se que, além de sua ação antifúngica, antibacteriana e antisséptica, vêm apresentando uma ação autolítica na presença de tecido necrótico. O desbridamento do tecido desvitalizado ou necrótico possibilita a cicatrização, promovendo o aparecimento de tecido de granulação, estimulando a neoangiogênese e a fagocitose, atraindo macrófagos para o local da ferida. Um estudo desenvolvido com 10 pacientes portadores de úlceras crônicas de membros inferiores demonstrou a indicação da própolis como forma farmacêutica de fácil utilização, como antiinfecciosa, propiciando a evolução satisfatória do processo de cicatrização $^{(9)}$. Outros pesquisadores utilizaram a própolis concentrada no tratamento das úlceras de pressão. A própolis, como uma resina das plantas colhidas pelas abelhas, promoveu nesta investigação uma ação bactericida e bacteriostática, confirmada pela manutenção do leito da ferida em condições ótimas para a cicatrização e pela observação da considerável regeneração tecidual ${ }^{(9-10)}$.

Em relação a variável sexo utilizou-se a metodologia de comparação do tempo de cicatrização não houve diferença em relação ao sexo do paciente. Ao aplicar a inferência paramétrica para o Tempo de Cicatrização, utilizando dois modelos probabilísticos: Exponencial e Weibull verificou-se que não existe relação entre o tempo de cicatrização e o tempo de existência da ferida, isto é, a cicatrização independe do tempo de existência da ferida. Ao iniciar o tratamento com a pomada de própolis o processo cicatricial apresentou sua evolução semelhantemente para toda e qualquer ferida. Portanto, pode-se inferir que os problemas de cicatrização surgem, em relação a cronicidade, por outros fatores, extrínsecos e intrínsecos, e não apenas pelo tempo de existência da mesma. Conclui-se que o tempo médio de cicatrização neste estudo foi de 13,10 semanas, o que significa, aproximadamente, três meses e meio de realização diária de curativos, sendo que a probabilidade da ferida não cicatrizar após 20 semanas foi de 25,91\%, ou melhor, a chance de cicatrização foi de $74,09 \%$ antes da $20^{a}$ semana. Esse resultado demonstra, em princípio, a otimização da cicatrização com essa terapêutica ${ }^{(10)}$.

$\mathrm{O}$ cuidar de pessoas com feridas tem por desafio o conhecimento dos diferentes fatores que envolvem a cicatrização e sua inter-relação com o processo saúdedoença-cuidado na sua integralidade ${ }^{(10)}$ e a terapêutica com a pomada de própolis pode corroborar com esse pressuposto.

\section{CONCLUSÕES}

Os resultados deste estudo permitiram aprofundar a avaliação da eficácia da própolis em feridas crônicas, conhecendo e compreendendo melhor os fatores que interferem na utilização da mesma, ou seja:

- a ação terapêutica, asséptica e como uma ferramenta de fácil utilização e baixo custo para o cuidado tópico de feridas crônicas;

- o tempo médio de cicatrização das feridas crônicas observadas neste estudo que foi de 13,10 semanas, o que possibilitou identificá-la como um estímulo para a cicatrização; 
O tratamento e prevenção das úlceras crônicas devem ter prioridade nas ações de saúde pública em nosso país, considerando as dificuldades relatadas pelos pacientes e familiares, quanto ao custo elevado e tempo do tratamento até a cura. A reabilitação e integração destes pacientes dependerão de esforços conjuntos de profissionais e da comunidade onde estão inseridos.

A avaliação do profissional de saúde é primordial para prevenir incapacidades e estimular o enfrentamento do problema como desafio para a cura.

\section{REFERÊNCIAS}

1. Moura LPP. Produção de própolis e seu efeito de longevidade das operárias e desenvolvimento de colméias de Apis mellifera africanizadas [tese de doutorado]. Faculdade de Ciências Agrárias e Veterinária da Universidade de São Paulo; Jaboticabal, 2001.

2. Franco SL. Própolis: Otimização do processo extrativo. Desenvolvimento de técnicas de controle de qualidade e produção de forma farmacêutica sólida [tese de doutorado]. Faculdade de Ciências Farmacêuticas da Universidade Estadual Paulista; Araraquara, 2001.

3. Pereira MG. Epidemiologia: teoria e prática. 6 a reimpressão.
Rio de Janeiro: Guanabara Koogan; 1995. p. 270.

4. Gogia PP. Feridas: tratamento e cicatrização. Rio de Janeiro: Revinter; 2003.192 p.

5. Jorge SA, Dantas, SRPE. Abordagem multiprofissional do tratamento de feridas. Rio de Janeiro: Atheneu; 2003. p.247-59.

6. Hess CT. Tratamento de feridas e úlceras, $4^{\text {a }}$. ed. Rio de Janeiro: Reichman \& Affonso Editores; 2002.

7. Colosimo EA. Análise de sobrevivência aplicada. $46^{\mathrm{a}}$ Reunião Anual da Região Brasileira da Sociedade Internacional de Biometria (RBRAS) e $9^{\circ}$ Simpósio de Estatística Aplicada à Experimentação Agronômica (SEAGRO); ESALQ/USP, Piracicaba, SP; 7 a 13 de julho de 2001.

8. Santos VLCG. Avanços tecnológicos no tratamento de feridas e algumas aplicações em domicílio. In: Duarte YAO, Diogo MJE. Atendimento domiciliar: um enfoque gerontológico. 1'a ed, São Paulo: Atheneu; 2000. p.265-306.

9. Bernardo CLE, IAFS Colavitti C, Garcia C. Própolis cicatrizante e antibiótico natural. Rev Bras Enferm 1990; jan-dez; 43 (1,2,3/4): 101-106.

10. Azevedo IBS; Sampaio RF; Montes JC; Contreras RLL. Tratamento de escaras de decúbito com própolis. Rev Bras Enferm 1986; abr-set; 39(2/3): 33-7.

11. Orlandi MHF; Santos MJ; Santos MF. Assistência de enfermagem a portadores de flebopatias e/ou linfopatias. In: Thomaz JB, Belczack, CEQ. Rio de Janeiro: RUBIO; 2006. p. 889-894. 